\section{Endogenous Growth Substances in Xylem and Shoot Tip Diffusate of Lychee in Relation to Flowering}

\author{
Wen-Shaw Chen \\ Department of Horticulture, National Chia-yi Institute of Agriculture, \\ Chia-yi City, Taiwan, Republic of China
}

Additional index words. cytokinins, gibberellins, IAA, ABA, Litchi chinensis

\begin{abstract}
The changes in cytokinins and gibberellins in xylem sap of lychee (Litchi chinensis Sonn. cv. Heh yeh) trees were investigated at the stages of leaf expansion, dormant bud (when apical leaves are dropped), 30 days before flower bud formation, flower bud formation, and full bloom of grafted field-grown lychee trees. Also; the diffusible IAA and ABA in diffusate from shoot tips were examined at the successive stages of development. High gibberellin was found in the xylem sap at the stage of leaf expansion. A constant level of IAA was maintained through the five growth stages. At 30 days before flower bud formation, ABA increased dramatically. Concurrently, total cytokinin content increased in the xylem sap, reaching a maximum during flower bud formation and full bloom. Gibberellin content in the xylem sap was at a low level 30 days before flower bud formation and through the stage of flower bud formation.
\end{abstract}

Lychee, a sub-tropical evergreen tree of the Sapindaceae family, produces a delicious and economically important fruit. In recent years, the market price of lychee has dropped steeply in the "on" year, depressing the incomes of farmers. If flowering could be controlled, this problem could be alleviated. Nakata (1955) obtained flowering of lychee trees sprayed with various concentrations of sodium naphthaleneacetic acid (NAA). However, attempts to induce flower bud formation with NAA have resulted in chemical injury in Taiwan. The flowering response to chemical treatment is still not clear: Chen and $\mathrm{Ku}$ (1988) reported that, when kinetin at $200 \mathrm{ml} \cdot \mathrm{mg}^{-1}$ was applied within 20 days after ethephon at $200 \mathrm{ml} \cdot \mathrm{mg}^{-1}$ had been applied in the September dry season, flower bud formation was $80 \%$ higher than in the control, and panicle emergence was 1 month earlier. These results may be favorable for the grower. The aim of the present study was to obtain information on natural hormone balance of lychee during the flowering process.

Eight-year-old, grafted lychee trees, grown in the field at Chia-yi Agricultural Experiment Station, were used throughout this investigation. Sixty uniform shoots (5 months old) were selected. Shoot length was measured and xylem sap sampled at leaf expansion (5 Aug.), bud dormancy (1 Sept.), 30 days before flower bud formation (28 Oct.), flower bud formation (22 Nov.), and full bloom (10 Jan.). Flower bud formation was

Received for publication 21 Nov. 1988. I gratefully acknowledge financial support from National Science Council Grant NSC75-0409-B021-05, Republic of China, and I thank Chi-Yu Chen for skillful technical assistance of GC-MS analysis. The cost of publishing this paper was defrayed in part by the payment of page charges. Under postal regulations, this paper therefore must be hereby marked advertisement solely to indicate this fact.
Table 1. Volume of xylem exudate at successive growth stage in lychee.

\begin{tabular}{lc}
\hline \hline Growth stage & $\begin{array}{c}\text { Volume of xylem sap } \\
\text { (ml per } 10 \text { terminal } \\
\text { shoots) }\end{array}$ \\
\hline Leaf expansion & $40 \pm 1$ \\
Dormant bud & $2 \pm 1$ \\
Thirty days before & $28 \pm 3$ \\
$\quad$ flower bud formation & $32 \pm 3$ \\
Flower bud formation & $41 \pm 2$ \\
Full bloom & \\
\hline
\end{tabular}

${ }^{2}$ Collected at $0830 \mathrm{HR}$.

$1 \mathrm{~N} \mathrm{NaOH}$ and partitioned four times with water-saturated n-butanol $(\mathrm{BuOH})$. The $n$ butanol phase was evaporated in a vacuum. The EtOAc and $\mathrm{BuOH}$ phases were individually passed through a Sep-Pak $\mathrm{C}_{18}$ cartridge and then a Sephadex LH-20 column for cytokinin analysis. The analytical procedures for gibberellin (GA) were similar to those of Chen (1987). GC-Selected Ion Current Monitoring was performed using a Hewlett-Packard 5970 mass spectrometer that was interfaced by a glass jet separator with a Hewlett-Packard 5890-A gas chromatograph. The gibberellins were chromatographed using a capillary column packed with OV-101. Samples $(1.0 \mu \mathrm{l})$ were injected into the column at $180 \mathrm{C}$. Following a $2-\mathrm{min}$ isothermal hold, the temperature was programmed $10 \mathrm{C}-\mathrm{min}^{-1}$ until the column was at $210 \mathrm{C}$. When the column reached $215 \mathrm{C}$, the rate was increased to $20 \mathrm{C} \cdot \mathrm{min}^{-1}$ until the column reached the maximum of $260 \mathrm{C}$. For each GA, three fragments with the following m/e values were monitored: $\mathrm{GA}_{1}, 506(81)$, 448 (100), 207 (60); GA , 418 (20), 284 (100), 224 (70); $\mathrm{GA}_{17}, 492$ (70), 460 (100), 208 (20); GA 419 (80), 418 (100), 375 (70). The dwell time of each fragment monitored was $200 \mathrm{~ms}$.

At successive growth stages, 2-cm-long shoot tips were excised and placed on agar medium for $48 \mathrm{hr}$ in darkness at 20C. The agar was soaked with $200 \mathrm{ml}$ of ether at 0C for $24 \mathrm{hr}$, and the filtrate reduced to the aqueous phase in vacuo. The analytical procedures for IAA and ABA in the shoot tip diffusates by HPLC and GC were similar to those of Chen (1987).

After addition to plant extracts, the following radioactive growth substances were used as internal standards determining the

Table 2. Cytokinin-like activity in extracts of xylem sap from lychee.

\begin{tabular}{|c|c|c|c|c|}
\hline \multirow[b]{2}{*}{ Growth stage } & \multicolumn{3}{|c|}{$\begin{array}{l}\text { Cytokinin-like substances }^{2} \\
\text { (mg.kg-1 of xylem sap) }\end{array}$} & \multirow{2}{*}{$\begin{array}{c}\text { Kinetin equivalent } \\
\left(\mathrm{mg} \cdot \mathrm{kg}^{-1} \text { of xylem sap }\right.\end{array}$} \\
\hline & $t-Z$ & $\mathrm{t}-\mathrm{ZR}$ & 2iPA & \\
\hline Leaf expansion & $2.4 \pm 0.8$ & $3.3 \pm 0.6$ & $2.8 \pm 0.4$ & $12.3 \pm 2.3$ \\
\hline Dormant bud & $3.1 \pm 0.1$ & $3.8 \pm 0.9$ & $3.1 \pm 0.2$ & $13.2 \pm 1.9$ \\
\hline \multicolumn{5}{|l|}{ Thirty days before } \\
\hline flower bud formation & $7.9 \pm 1.1$ & $8.9 \pm 1.8$ & $6.7 \pm 0.7$ & $31.2 \pm 2.3$ \\
\hline Flower bud formation & $10.1 \pm 2.2$ & $18.1 \pm 1.1$ & $10.3 \pm 0.5$ & $42.1 \pm 1.6$ \\
\hline Full bloom & $15.2 \pm 2.3$ & $14.5 \pm 1.8$ & $15.4 \pm 1.4$ & $61.5 \pm 1.2$ \\
\hline
\end{tabular}

${ }^{2}$ Quantitative estimates are based on UV analysis by HPLC and subsequently validated by soybean cotyledonary callus assay. The bioactivity correlated well with the UV peak area, which in turn was calibrated with a standard curve for the authentic cytokinins: $t-Z$, trans-zeatin; $t-Z R$, trans-zeatin riboside; 2iPA, N-(3-methyl-2-butenyl)-1H-purin-6-amine riboside. 
Table 3. Elution of gibberellins from analytical reverse HPLC system at successive growth stages of lychee.

Gibberellins $^{2}$

(mg.kg ${ }^{-1}$ of xylem sap)

\begin{tabular}{lcccrr} 
Growth stage & \multicolumn{1}{c}{$\mathrm{A}_{\downarrow}$} & \multicolumn{1}{c}{$\mathrm{A}_{4}$} & \multicolumn{1}{c}{$\mathrm{A}_{17}$} & \multicolumn{1}{c}{$\mathrm{A}_{20}$} & \multicolumn{1}{c}{ Total } \\
\hline Leaf expansion & $2.9 \pm 0.4$ & $3.1 \pm 0.3$ & $15.2 \pm 0.2$ & $13.1 \pm 0.3$ & $34.3 \pm 0.4$ \\
$\begin{array}{l}\text { Dormant bud } \\
\text { Thirty days before }\end{array}$ & $1.3 \pm 0.1$ & $1.4 \pm 0.8$ & $3.2 \pm 0.2$ & $4.1 \pm 0.1$ & $10.0 \pm 0.2$ \\
$\quad$ flower bud formation & $1.0 \pm 0.3$ & $0.8 \pm 0.2$ & -- & - & $1.8 \pm 0.2$ \\
Flower bud formation & $0.1 \pm 0.01$ & $0.6 \pm 0.1$ & --- & -- & $0.7 \pm 0.1$ \\
Full bloom & $0.2 \pm 0.1$ & $0.7 \pm 0.1$ & --- & --- & $0.9 \pm 0.1$ \\
\hline
\end{tabular}

${ }^{2}$ The partially purified acidic extract was fractionated by a linear gradient of methanol (30\% to $\left.100 \%\right)$ in $1 \%$ aqueous acetic acid, run in $30 \mathrm{~min}$, and each fraction was bioassayed with dwarf rice cultivar Tan-ginbozu. Further identification and quantification were performed with GC-MS-SIM analysis.

Table 4. Contents of endogenous IAA and ABA, and shoot growth of lychee. ${ }^{2}$

\begin{tabular}{lccc}
\hline \hline & \multicolumn{2}{c}{$\begin{array}{c}\text { Growth regulator } \\
\text { (ng per 10 shoot tips) }\end{array}$} & Shoot growth \\
\cline { 2 - 3 } Growth stage & IAA & ABA & \\
\hline Leaf expansion & $100 \pm 4$ & $40 \pm 2$ & $60 \pm 1$ \\
Dormant bud & $92 \pm 2$ & $98 \pm 4$ & 0 \\
Thirty days before & & & \\
$\quad$ flower bud formation & $93 \pm 1$ & $97 \pm 4$ & $35 \pm 2$ \\
Flower bud formation & $98 \pm 2$ & $99 \pm 3$ & $3 \pm 1$ \\
Full bloom & $96 \pm 2$ & $96 \pm 4$ & 0
\end{tabular}

${ }^{\mathrm{a}} \mathrm{IAA}$ was determined by HPLC-fluorescence and electrochemical detectors. ABA was estimated with HPLC and GC-ECD analysis.

losses through purification and chromatography: $\left[2-^{14} \mathrm{C}\right] \mathrm{ABA} \quad 0.7 \mathrm{kBq} \cdot \mathrm{mol}^{-1} ;[1-$ $\left.{ }^{14} \mathrm{C}\right] \mathrm{IAA} 4.94 \mathrm{kBq} \cdot \mathrm{mol}^{-1}$; $\left[8-{ }^{14} \mathrm{C}\right.$ ]zeatin 1.02 $\mathrm{kBq} \cdot \mathrm{mol}^{-1}$; and $\left.{ }^{3} \mathrm{H}\right] \mathrm{GA}_{4} 0.52 \mathrm{kBq} \cdot \mathrm{mol}^{-1}$. The recovery of radioactive growth substances was estimated by measuring the radioactivity using liquid scintillation counting.

The flow of xylem exudate at leaf expansion, 30 days before flower bud formation, and at flower bud formation was higher than at the dormant bud stage (when only a small volume of xylem sap was obtained). Xylem sap also was high at full bloom (Table 1). The recovery of radiolabeled IAA, ABA, and $\mathrm{GA}_{4}$ for the diffusate of shoot tips and xylem sap of lychee shoots was $80 \% \pm 0.3 \%, 79 \%$ $\pm 1.5 \%$ and $81 \% \pm 0.1 \%$, respectively, and that of labeled zeatin was $65 \% \pm 0.4 \%$.

Three cytokinin-like substances resembling $\mathrm{t}-\mathrm{Z}, \mathrm{t}-\mathrm{ZR}$, and 2iPA were found at all development stages (Table 2). More cytokinins were obtained from the xylem sap at 30 days before flower bud formation, flower bud formation, and full bloom than during leaf expansion and from dormant buds. The data suggest that high endogenous cytokinins synthesized in the roots may play an important role in controlling the formation and development of the inflorescence. Chen (1987) reported that increase of cytokinins in the xylem sap of mango is associated with flower bud formation. The results in the present paper demonstrate that the high content of cytokinin-like substances is correlated with flower bud formation in lychee. The $\mathrm{t}-\mathrm{Z}$ and $\mathrm{t}-\mathrm{ZR}$ are the translocational form cytokinins that recently also have been identified in the xylem sap of tomato (Davey and van Staden, 1976), whereas 2iPA have been found in young fruits of mango (Chen, 1983). Thus, $\mathrm{t}-\mathrm{Z}, \mathrm{t}-\mathrm{ZR}$, and $2 \mathrm{iPA}$ appear to occur commonly in higher plants and suggest a correlation between these various cytokinins and flower bud formation.

The gibberellins were highest at leaf expansion and decreased at the dormant bud stage. There was a continuous low level of gibberellins in the xylem sap from 30 days before flower bud formation through full bloom (Table 3). Menzel (1983) reported that low temperature and moisture stress seemed to restrict vegetative growth and promote floral initiation in lychee. Results here indicate that low levels of endogenous gibberellins are closely related to floral initiation in lychee. Leaf expansion and stem growth are preceded by a steep rise in the level of $\mathrm{GA}_{17}$ and $\mathrm{GA}_{20}$. Because exogenous $\mathrm{GA}_{17}$ and $\mathrm{GA}_{20}$ are able to cause stem growth in lychee plants (data not shown), the major factor in the control of stem growth in lychee could be the availability of endogenous $\mathrm{GA}_{17}$ and $\mathrm{GA}_{20}$. The exact metabolic relationship between the endogenous GAs must be ascertained before a clear picture of the mechanism of stem growth or flower bud formation can be made.

Diffusible IAA maintained a constant level during the five growth stages, but the total amount of free ABA increased with the age of the shoots and was abundant 30 days before flower bud formation, at flower bud formation, and at full bloom (Table 4). Decrease in shoot growth was associated with high $\mathrm{ABA}$ content. It is premature to draw conclusions about a possible role for ABA in bud dormancy and stem growth. Since the physiological processes involved are not wellunderstood, I must rely to a large extent on the correlation between ABA content and the anatomical state of flower bud formation.

\section{Literature Cited}

Chen, W.S. 1983. Cytokinins of the developing mango fruit: Isolation, identification, and changes in levels during maturation. Plant Physiol. 71:356-361.

Chen, W.S. 1987. Endogenous growth substances in relation to shoot growth and flower bud development of mango. J. Amer. Soc. Hort. Sci. 112:360-363.

Chen, W.S. and M.L. Ku. 1988. Ethephon and kinetin reduce shoot length and increase flower bud formation in lychee. HortScience 23:1078.

Davey, J.E. and J. van Staden. 1976. Cytokinin translocation: changes in zeatin and zeatin riboside levels in the root exudate of tomato plant during development. Planta 130:67-72.

Menzel, C.M. 1983. The control of floral initiation in lychee: A review. Scientia Hort. 21:201215.

Nakata, S. 1955. Floral initiation and fruit set in lychee with special reference to the effect of sodium naphthaleneacetate. Bot. Gaz. 117:126134. 